\title{
Differential regulation of survivin by $p 53$ contributes to cell cycle dependent apoptosis
}

\author{
Yan JIN, Yong WEI, Lei XIONG, Ying YANG, Jia Rui WU* \\ Laboratory of Molecular Cell Biology, Institute of Biochemistry and Cell Biology, Shanghai Institutes for Biological Sciences, \\ Chinese Academy of Sciences, 320 Yue Yang Road, Shanghai 200031, China
}

\begin{abstract}
Recent studies indicate that cell-cycle checkpoints are tightly correlated with the regulation of apoptosis, in which p53 plays an important role. Our present works show that the expression of E6/E7 oncogenes of human papillomavirus in HeLa cells is inhibited in the presence of anti-tumor reagent tripchlorolide (TC), which results in the up-regulation of p53 in HeLa cells. Interestingly, under the same TC-treatment, the cells at the early S-phase are more susceptible to apoptosis than those at the middle S-phase although p53 protein is stabilized to the same level in both situations. Significant difference is exhibited between the two specified expression profiles. Further analysis demonstrates that anti-apoptotic gene survivin is up-regulated by p53 in the TC-treated middle-S cells, whereas it is down-regulated by p53 in the TC-treated early-S cells. Taken together, the present study indicates that the differential p53-regulated expression of survivin at different stages of the cell cycle results in different cellular outputs under the same apoptosis-inducer.
\end{abstract}

Keywords: apoptosis, cell cycle, p53, survivin, HeLa cell.

\section{INTRODUCTION}

The balance between cell cycle procession and apoptosis is crucial for normal tissue homeostasis. Any breaks of this balance, which leads to inappropriate cell death and/or abnormal proliferation, can result in diseases even tumorigenesis [1,2]. Numerous works have been done to discover the mechanism of balancing apoptosis and cell cycle progression, and a number of observations have indicated that the regulation of apoptotic process is tightly coupled with the surveillance mechanisms of the cell-cycle checkpoints [3-6].

Recent studies have identified several molecules common to the regulation of the cell cycle and apoptosis. Dual roles of these molecules such as c-Myc, p53, survivin and Bcl-2 provide a rational linkage between cell cycle and apoptosis [3, 6-9]. Among these factors, tumor suppressor p53 performs a pivotal role switching between cell cycle regulation and apoptosis induction $[10,11]$. Functional p53 mainly contributes as a transcriptional factor with both capabilities of transactivation and transrepres-

\footnotetext{
*Correspondence: Jia Rui WU

Tel: +86-21-54921128; Fax: +86-21-54921011;

E-mail: wujr@sibs.ac.cn
}

sion. Hundreds of p53-responsive genes have been identified [10-12]. It was reported that differential transregulation by $\mathrm{p} 53$, which means transactivation or transrepression of different subsets of p53 target genes, was important to determine what downstream event would be elicited [13]. Nonetheless, more details about the differential transregulation of p53 remains to be elucidated.

Many chemotherapeutic agents have been used for tumor therapy by inducing apoptosis of tumor cells. It was reported that cells treated with some antitumor agents had different susceptibility to apoptosis in a cell cycle related manner [14]. This cell cycle stage-dependent susceptibility to apoptosis was also found in cells treated with staurosporine [15] and arsenite [16]. This different susceptibility may be explained by the variety of the lesion severity and the repair ability to the lesion. It is supported by the evidence that p53 can modulate the activity of base excision repair in a cell cycle-specific manner after genotoxic stress induced by $\gamma$-irradiation [17]. However, the mechanism controlling the cell-cycle dependent susceptibility to apoptosis is still unknown.

Triptolide is a diterpene triepoxide purified from the Chinese herb Tripterygium Wilfordii Hook. It has potent antiproliferative and proapoptotic activities with many types of cancer cells and transformed cell line in vitro and in 
vivo [18-20]. Recent studies show that triptolide executes anti-neoplastic effect [21-23] and a functional p53 is required for the proapoptotic effect [24]. Tripchlorolide (TC), a derivate of triptolide with similar activity and much lower toxicity [25], has shown its anti-neoplastic activities against leukemic, lung and other tumor cells. Our previous works reported that $\mathrm{TC}$ disturbed the cell cycle and induced apoptosis in Chinese hamster ovary (CHO) cells, which resulted from degradation of c-Myc and dysfunctional p53 [26, 27]. In this study, we demonstrated that TC inhibited the expression of viral oncoprotein E6/E7, which resulted in an up-regulation of p53 in HeLa S3 cells. TC induced a p53-mediated apoptosis in Hela S3 cells. Moreover, the susceptibility to apoptosis was cell-cycle specific when the cycling cells were treated with TC. To clarify the molecular foundation, we monitored the expression profiles of TC-treated cells at different cell-cycle stages with microarray assay. Combined the array data with further analysis of survivin, we conclude that the differential expression of survivin regulated by p53 at different cell cycle stages plays an important role in the cellcycle dependent apoptosis under the TC treatment.

\section{MATERIALS AND METHODS}

\section{Cell culture and synchronization}

HeLa S3 cells (ATCC) were maintained in Dulbecco's Modified Eagle's Medium (DMEM, Gibco BRL) supplemented with 5\% fetal bovine serum (FBS, Gibco BRL) at $37^{\circ} \mathrm{C}$ in $5 \% \mathrm{CO}_{2}$. The cells were synchronized at $\mathrm{G} 1 / \mathrm{S}$ boundary with $2 \mathrm{mM}$ hydroxyurea (HU, Calbiochem) for $24 \mathrm{~h}$, and then were released in the HU-free medium for $5 \mathrm{~min}$ (the early-S cells) and for $3 \mathrm{~h}$ (the middle-S cells), respectively.

\section{Flow cytometric analyses}

For the DNA content analysis, the cells were collected and fixed with 70\% ethanol. The fixed cells were treated with RNase A and stained with propidium iodide (PI, Sigma). The DNA contents were measured with a flow cytometer (FACScan). For the Annexin V assay, the cells were stained with Annexin V-FITC according to the manufacturer's protocol (PharMingen). For M30-PI double staining, the cells were subjected to the CytoDEATH M30 assay according to the manufacture's instruction (Roche Molecular Biochemicals).

\section{Isolation of cytosolic and mitochondrial fractions}

HeLa S3 cells were treated with a digitonin-buffer $(20 \mathrm{mM}$ Hepes$\mathrm{KOH}, \mathrm{pH} 7.3,110 \mathrm{mM} \mathrm{KAc}, 5 \mathrm{mM} \mathrm{NaAc}, 2 \mathrm{mM} \mathrm{MgAc}_{2}, 1 \mathrm{mM}$ EGTA and $200 \mu \mathrm{g} / \mathrm{ml}$ digitonin) on ice for $10 \mathrm{~min}$ to permeabilize the cell membrane. The cell lysate was then centrifuged at $10,000 \mathrm{~g}$ at $4^{\circ} \mathrm{C}$ for $15 \mathrm{~min}$. The supernatant was collected as a cytosolic fraction, and the pellet was as a mitochondria-fraction.

\section{Western-blotting analysis}

HeLa S3 cells were lysed with $1 \times$ SDS-loading buffer $(50 \mathrm{mM}$ Tris-Cl, pH 6.8, $100 \mathrm{mM}$ DTT, 2\% SDS, 10\% glycerol and $0.1 \%$ bromophenol blue). In the case of digitonin-permeabilized cells, the cytosolic fraction was mixed with equal volume of $2 \times$ SDS-loading buffer, and the mitochondrial fraction was suspended with $1 \times$ SDSloading buffer. Western-blotting was carried out with primary antibodies including anti-p53 and phospho-p53 (Ser15) (Cell Signaling); anti-Bax, anti-Cytochrome $c$, anti- $\beta$-actin (Santa Cruz); anti-Bcl-2, Sigma; anti-COX 4 (Molecular Probes); anti-survivin (PharMingen), respectively. The proteins were detected by enhanced chemiluminescence (ECL-plus, Amersham Pharmacia Biotech).

\section{Northern blot analysis}

Total RNA of the cells was isolated using the TRIzol (Invitrogen) according to the manufacturer's protocol. Purified total RNA was electrophoresed on $1 \%$ formaldehyde denatured agarose gel and transferred to Hybond-N (Amersham Pharmacia Biotech). Hybridization was performed using ExpressHyb Hybridizaton Solution (BD Bioscience) according to the manufacturer's instruction. The probes were labeled with random primer DNA labeling kit (Promega) and the probe templates were generated by RT-PCR amplification from the RNA of HeLa S3 cells with the following primer pair:

p53: f-CCCCTCCTGGCCCCTGTCATCT and r-GGGCGGGG GTGTGGAATCAAC, GAPDH: f-CGCCAGCCGAGCCACATC and r-GCCAGCATCGCCCCACTTGA, E6-E7: f-AGGGAGTAA CCGAAAACG and r-CATAAAACCAGCCGTTAC.

\section{Plasmid construction and transfection}

The full-length of Chinese hamster $\mathrm{p} 53$ coding sequence was obtained by RT-PCR from CHOC400 cells, which contains a point mutation in its DNA binding domain [28]. This mutated-p53 insert was cloned into SalI/BamHI sites of pEGFP-C1 (CLONTECH) to generate pEGFP-cgTP53 as a p53-dominant negative plasmid. HeLa $\mathrm{S} 3$ cells were transfected with pEGFP-cgTP53 by Lipofectamine ${ }^{\mathrm{TM}}$ 2000 system (GIBCO BRL).

The $1.1 \mathrm{k}$ sequence of the survivin promoter region of $\mathrm{HeLa} \mathrm{S} 3$ was obtained by PCR-based amplification as described [29]. The plasmid Sur-p was constructed by inserting the survivin promoter on the upstream of the luciferase gene in pGL3-Basic (Promega). An EGFP fused p53 dominant negative construct was co-transfected with the plasmid Sur-p for the experiments on suppression of p53 activities. pEGFP-C1 was also used as a control. HeLa S3 cells were transfected with Sur-p by Nucleofector assay according to the manufacture's instruction (Amaxa biosystems).

\section{RNAi of survivin}

The Sur-RNAi plasmid was constructed with pSUPER RNAi System (OligoEngine). A pair of 64-nt oligonucleotides each containing a 19-nt sequence (5'-gatccctTAC ATT CAA GAA CTG GCC CttcaagagaGGG CCA GTT CTT GAA TGT Atttttggaaa-3' and 5'agcttttccaaaaaTAC ATT CAA GAA CTG GCC CtctcttgaaGGG CCA GTT CTT GAA TGT Aggg-3') derived from the survivin transcript were inserted into the vector pSUPER between BgIII and HindIII sites according to the manufacture's instruction. HeLa S3 cells were transfected with Sur-RNAi by Nucleofector assay (Amaxa biosystems).

\section{Microarray assay}

Microarray assay was performed with Atlas ${ }^{\mathrm{TM}}$ Human Apoptosis Array containing 205 cell cycle-related and apoptotic genes as described in the manufacture's instruction (BD Biosciences). Briefly, the poly-A RNA from HeLa S3 cells was purified, and labeled with 
A

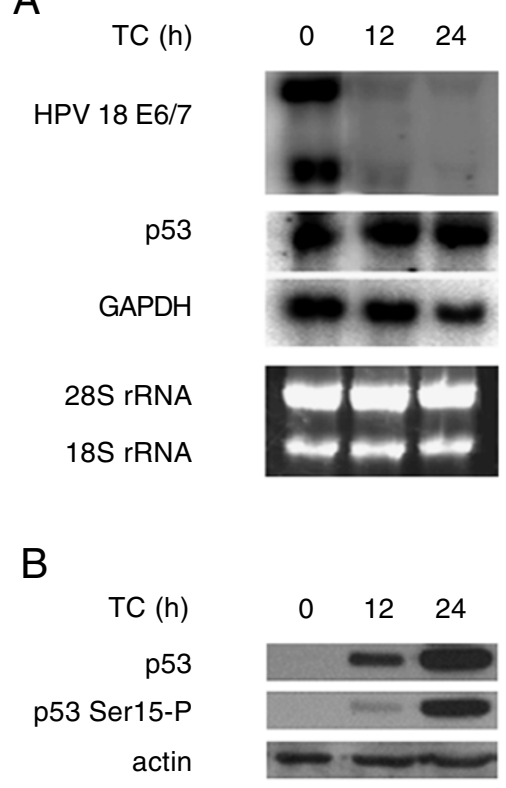

Fig. 1 p53 was restored and activated in HeLa cells under TC treatment. Exponentially growing HeLa S3 cells were treated with $15 \mathrm{ng} / \mathrm{ml} \mathrm{TC}$ for 0,12 and $24 \mathrm{~h}$, respectively. (A) Northern blot of E6/ E7 and p53. GAPDH was used as an internal standard of the total mRNA, while the $18 \mathrm{~S} / 28 \mathrm{~S}$ rRNA stained with ethidium bromide was used as loading control of the total RNA. (B) Western-blotting of p53 and p53Ser15-P. Actin was used as sample-loading control.

Atlas ${ }^{\mathrm{TM}}$ Pure Total RNA Labeling System. The Atlas ${ }^{\mathrm{TM}}$ Human Apoptosis Array was hybridized with the ${ }^{32} \mathrm{P}$-labeled cDNA samples and scanned by PhosphorImager (Molecular Dynamics). The signals were analyzed using the ImageQuant software (Molecular Dynamics). The relative expression of housekeeping genes served to normalize gene expression levels, and two separate experiments were performed.

\section{Luciferase assay}

HeLa S3 cells were transfected with Sur-p and other plasmids, respectively. After a 12-h post-transfection, the cells were synchronized with $2 \mathrm{mM}$ HU. The cells were harvested after the indicated TC-treatment. The promoter activity was measured with Luciferase Assay System (Promega). $\beta$-galactosidase expression plasmid pCH110 (Pharmacia Biotech Inc.) was co-transfected as an internal standard to normalize the luciferase activity ( $\beta$-Galactosidase Enzyme Assay System, Promega).

\section{RESULTS}

\section{p53 restoration and activation of HeLa cells by TC}

HeLa cell line is well known as a cervical cancer cell line with dormant $\mathrm{p} 53$ pathway for its infection of human papillomavirus 18 (HPV18), in which the viral protein E6 accelerates $\mathrm{p} 53$ degradation by binding to $\mathrm{p} 53$ protein $[30-$ 32]. However, when HeLa cells were treated with an potent anti-tumor reagent Tripchlorolide (TC), it was found that the E6/E7 mRNA was diminished significantly after 12-h treatment and was reduced to an undetectable level after 24-h treatment (Fig. 1A), whereas the mRNA level of p53 was increased 1.21- and 2.67-fold after 12- and 24-h treatment (normalized by GAPDH, Fig. 1A). Consistent with the abolition of E6 inhibition, $\mathrm{p} 53$ protein was stabilized and elevated significantly in the TC-treated HeLa $\mathrm{S} 3$ cells (Fig. 1B). These results indicated that TC-induced restoration of p53 was correlated to the combination of down-regulating the expression of E6/E7 mRNA and upregulating the expression of $\mathrm{p} 53 \mathrm{mRNA}$.

To identify whether $\mathrm{p} 53$ is activated in TC treated HeLa cells, we further assessed the phosphorylation level of $\mathrm{p} 53$. Fig. 1B showed the phosphorylation on Ser 15 of p53, which an early event in the activation of $\mathrm{p} 53$ responding to DNA damage [33, 34]. Furthermore, the transcriptional activation capability of p53 was demonstrated by the array analysis. We utilized the Atlas ${ }^{\mathrm{TM}}$ Human Apoptosis Array (BD Biosciences), which contains selected 205 cell-cyclerelated and apoptotic genes, to monitor the expression profiles of TC-treated HeLa cells. The results showed that a series of p53 inducing genes such as PIGs (PIG3, PIG7, PIG10, PIG11 and PIG12), p2 $1^{\text {WAFI/CIP1 }}$ and GADD45 were up-regulated significantly. Taken together, these results indicated the TC-induced restoration and activation of p53 of HeLa cells.

\section{p53 dependence of TC-induced apoptosis of HeLa cells}

To address whether apoptosis of HeLa cells is induced in the presence of $\mathrm{TC}$, we treated exponentially growing HeLa cells with $15 \mathrm{ng} / \mathrm{ml} \mathrm{TC}$ for $24 \mathrm{~h}$. An apoptotic population was identified from the TC-treated cells as measured by Annexin-V [35, 36] or M30 assay [37, 38] (Fig. $2 \mathrm{~A}, 2 \mathrm{~B})$. After the drug treatment, the adherent cells as less apoptotic population and the floating ones as completely apoptotic population were collected separately. Western-blotting assays showed that cytochrome $c$ release was observed in the floating cells, while it remained in the mitochondria-fractions of the adherent cells and the cells without TC treatment (Fig. 2C, compare lanes 9 to 7 and 8). Furthermore, almost all of the Bax proteins were translocated to mitochondria in the TC treated cells, whereas most remained in the cytosol in the untreated cells (Fig. 2C, compare lanes 5, 6, 8 and 9 to 4 and 7). Collectively, these results indicated that TC induced the apoptosis of HeLa cells through the mitochondrial-regulated apoptotic pathway.

To validate the contribution of p53 in the apoptosis induced with TC, the p53-dominant negative construct 
A $-\mathrm{TC}$

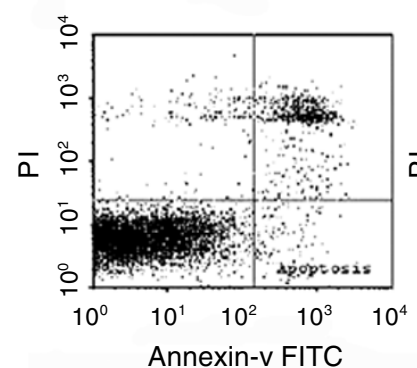

B

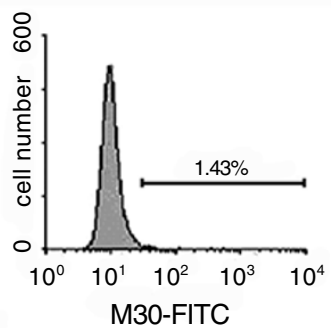

C

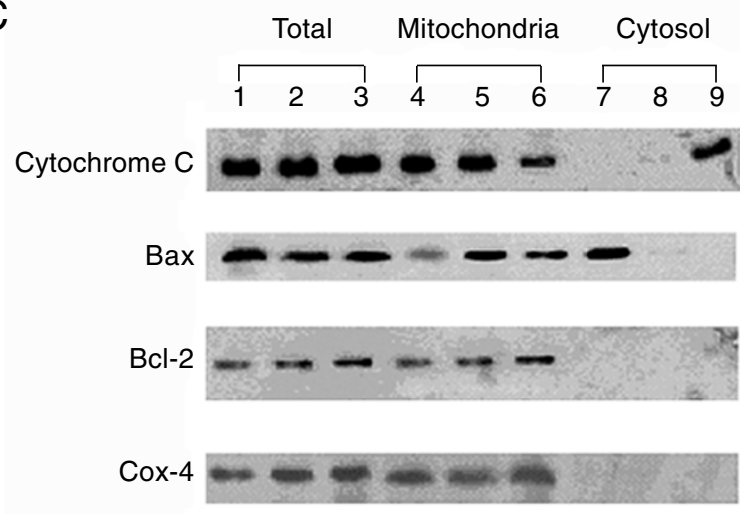

cgTP53-EGFP was introduced into HeLa cells, which contains a point mutation in its DNA binding domain [28] (see Materials and methods). After the transfection, the cells were treated with $15 \mathrm{ng} / \mathrm{ml} \mathrm{TC}$ for $24 \mathrm{~h}$, and then the condensed nuclei as the representative of apoptotic cells were counted under the fluorescent microscope. The results showed that the number of the apoptotic cells in the population of HeLa cells transfected with cgTP53-EGFP was significant lower than that in the population transfected with EGFP (mock) in the presence of TC (Fig. 2D), indicating that TC-induced apoptosis of HeLa cells is p53dependent.

\section{Cell-cycle dependence of TC-induced apoptosis}

In order to analyze the relationship between the cell cycle regulation and apoptosis, M30-PI double staining assay, which could discriminate apoptotic status as well as the cell-cycle phases of the same cell, was performed to asynchronous HeLa cells treated with TC for the indi-

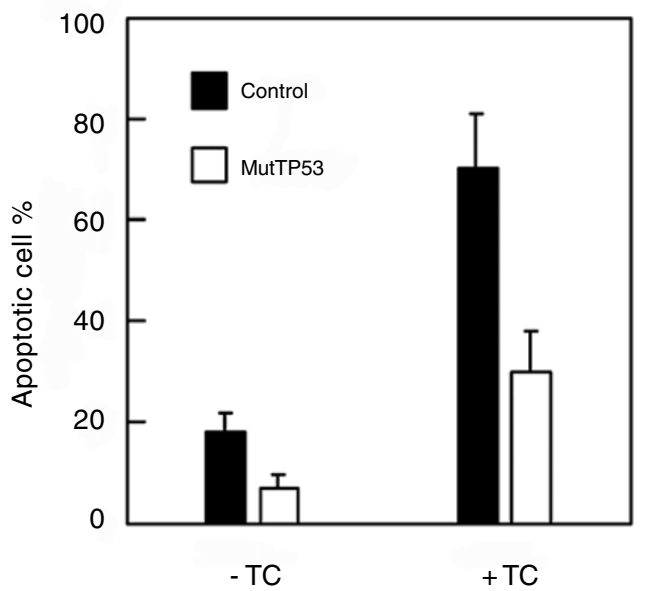

Fig. 2 The TC-induced apoptosis is p53 dependent in HeLa cells. Exponentially growing HeLa S3 cells were treated with $15 \mathrm{ng} / \mathrm{ml} \mathrm{TC}$ for $24 \mathrm{~h}$ and analyzed with flow cytometry. (A) Apoptotic cells measured by Annexin V assay. The cells were harvested and labeled directly with Annexin V-FITC and PI. (B) Apoptotic cells measured by M30 assay. The cells were labeled with M30 CytoDEATH antibody and measured by flow cytometry. (C) Western-blotting of Cytochrome $c$, Bax and Bcl-2 of HeLa cells. The untreated cells were collected as a total cell lysate (lane 1) and separated as the mitochondrial and cytosolic fractions (lanes 4, 7); the adherent cells after TC treatment were harvested as a total cell lysate (lane 2) and separated as the mitochondrial and cytosolic fractions (lanes 5,8); the floating cells after TC treatment were collected as a total cell lysate (lane 3) and separated as the mitochondrial and cytosolic fractions (lanes 6 , 9). A mitochondrial protein, Cox 4, was shown as the quality control of the fractionation. (D) Inhibition of the TC-induced apoptosis by mutated p53. Exponentially growing HeLa S3 cells were transfected with EGFP-cgTP53 plasmid (mutTP53) and EGFP-C1 vector (control), respectively. The transfected cells were treated with $20 \mathrm{ng} /$ $\mathrm{ml} \mathrm{TC}$ for $24 \mathrm{~h}$. The condensed apoptotic nuclei stained with DAPI were determined under the fluorescent microscope, of which the percentage of apoptotic cells was counted out of the EGFP-positive cells. Data shown are representative of three separate experiments (mean $\pm \mathrm{SD})$.

cated times. The flow cytometric analyses showed that the apoptotic cells in $\mathrm{S}$ phase were significantly more than that in non-S phase including $\mathrm{G}_{1}$ and $\mathrm{G}_{2} / \mathrm{M}$ phases (Fig. $3 \mathrm{~A}$ ), suggesting that the TC-treated cells within $\mathrm{S}$ phase very likely initiate the apoptosis.

To further address this question, HeLa cells synchronized at different stages of S phase were explored. HeLa cells synchronized at $\mathrm{G}_{1} / \mathrm{S}$ border by the treatment of hydroxyurea would progress into early-S phase directly after the releasing (as early-S cells) and into middle-S phase after 3-h releasing (as middle-S cells) (Fig. 4A). The synchronized early-S cells and middle-S cells were treated 
A

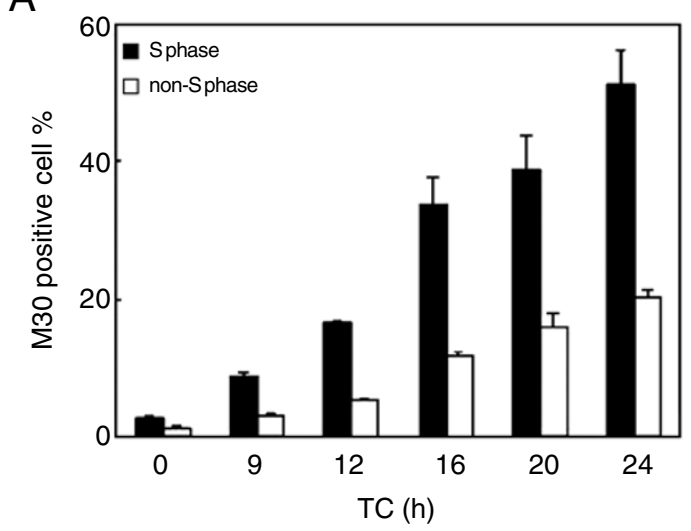

B

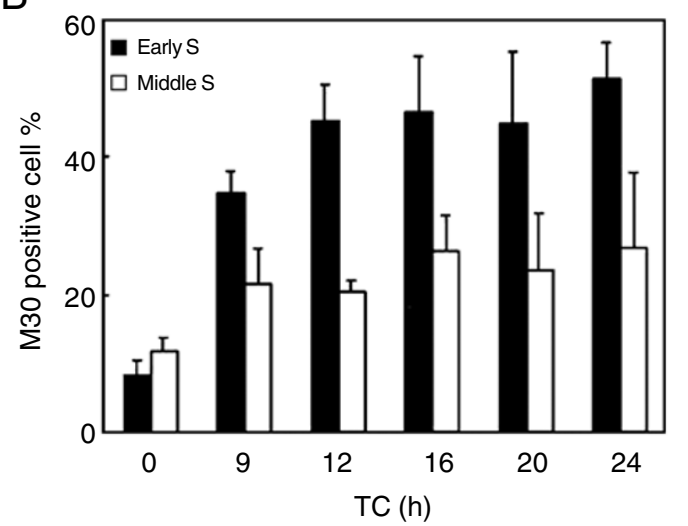

Fig. 3 Apoptosis induced by TC is cell-cycle dependent. (A) the apoptotic cells in the particular stages of cell cycle were measured. The exponentially growing HeLa S3 cells treated with $15 \mathrm{ng} / \mathrm{ml} \mathrm{TC}$ were harvested at indicated time points, and then double stained with M30 CytoDEATH antibody and PI. The populations of "S-phase" and "None S- phase" including G1 and G2/M phase were determined according to DNA content analysis through the flow cytometer. (B) the number of TC-induced apoptotic cells from the early-S or middle-S population was measured. The early S-phase and middle S-phase cells were prepared as described in Materials and Methods. The synchronized cells were treated with $15 \mathrm{ng} / \mathrm{ml} \mathrm{TC}$, and then harvested at indicated time points. Flow cytometric analyses were done with M30 CytoDEATH and PI double staining. Data shown are representative of three separate experiments $($ mean $\pm \mathrm{SD})$

with TC, respectively. It was showed that the TC-treated early-S cells slowed down its progression of $\mathrm{S}$ phase (Fig. 4A) and underwent a high level of apoptosis (Fig. 3B), whereas the middle S-phase cells treated with TC could progress to the next $\mathrm{G}_{1}$ phase within $12 \mathrm{~h}$ (Fig. 4A) and went a lower apoptotic degree (Fig. 3B). Taken together, these results suggest that TC-induced apoptosis of HeLa cells is cell-cycle dependent.

\section{Profiling of genes differentially expressed between early-S and middle-S cells under TC treatment}

To understand the molecular behaviors that result in the different susceptibility in TC-treated HeLa cells at different stages of S phase, we monitored the gene expression profiles with Atlas ${ }^{\mathrm{TM}}$ Human Apoptosis Array. The synchronized HeLa cells in early and middle $\mathrm{S}$ phase were treated with $15 \mathrm{ng} / \mathrm{ml} \mathrm{TC}$ for $13 \mathrm{~h}$, respectively. The array analyses showed that the expression profile in TC-treated early-S cells presented a tendency of down-regulation, among which the ratio of TC-treated sample/control of total 59 genes was below 0.5 . In contrast, the expression profile in TC-treated middle-S cells showed a tendency of up-regulation, among which the ratio of TC-treated sample/ control of total 52 genes was over 1.5 (Fig. 4B). These results suggest that RNA transcription machine in the early$\mathrm{S}$ cells is more sensitive to TC treatment than that of the middle-S cells.

Further analyses showed that few of the genes between the TC-treated early-S cells and middle-S cells had the same expression tendency (Fig. 4B). Interestingly, many pro-apoptotic genes were up-regulated in the early-S cells, whereas they were down-regulated in the middle-S cells. For example, the genes promoting apoptosis such as caspases 6 and 10 were up-regulated to 1.62- and 1.61fold, respectively, in TC-treated early-S cells, but downregulated to 0.55 - and 0.31 - fold, respectively, in TC-treated middle-S cells. In contrast, the microarray data showed that survivin, an inhibitor of apoptosis (IAP) protein [39], was down-regulated in the TC-treated early-S cells but up-regulated in the TC-treated middle-S cells. These results suggest that the output of the gene-expression network in the TC-treated early-S cells promotes apoptosis, whereas no such case was in the TC-treated middle-S cells.

\section{Survivin differentially expressed between early-S and middle-S cells under TC treatment}

Survivin is a member of IAP family involving in both the apoptotic regulation and the cell-cycle control $[39,40]$. In the present study, the expression patterns of survivin within the stages of the HeLa cell cycle were first analyzed. Consistent with the results of Altieri DC's lab [3], survivin was highly expressed in the G2/M phase and lowered in the G1 phase (Fig. 5A).

In order to investigate the expression of survivin of different cell cycle stages under TC treatment, early-S and middle-S cells were treated with $15 \mathrm{ng} / \mathrm{ml}$ TC for $13 \mathrm{~h}$, 
A

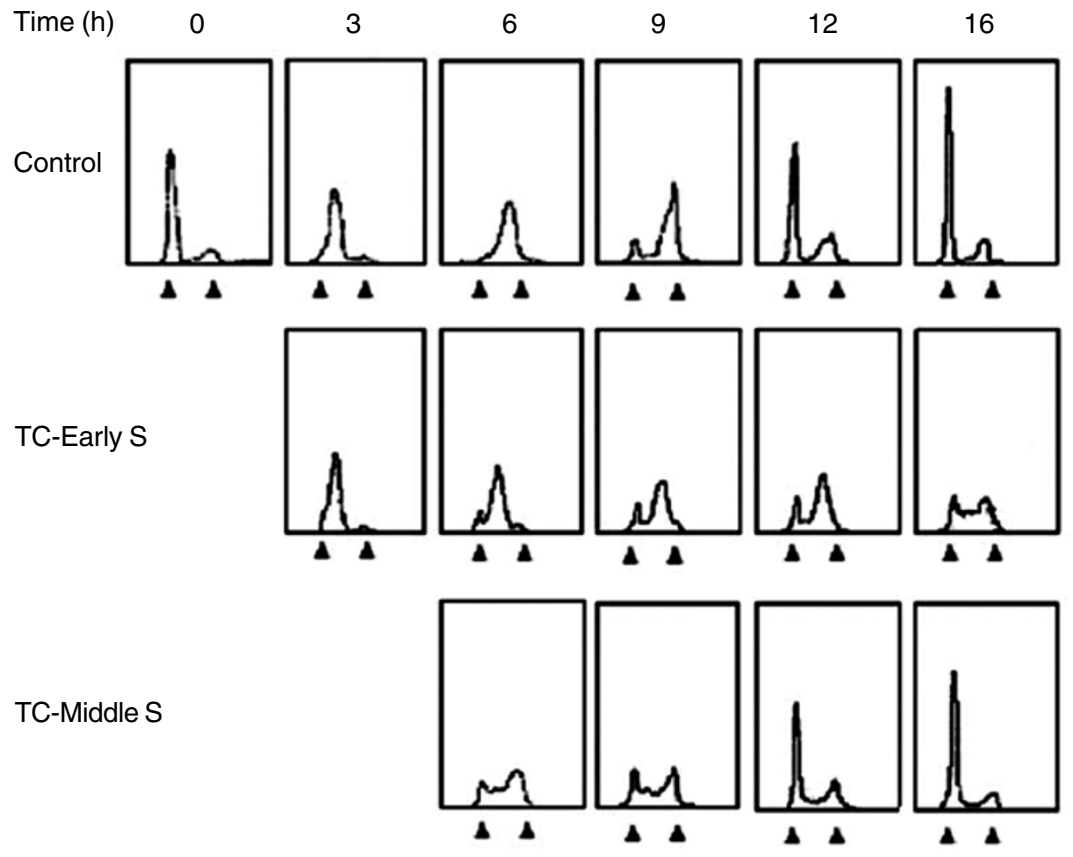

B

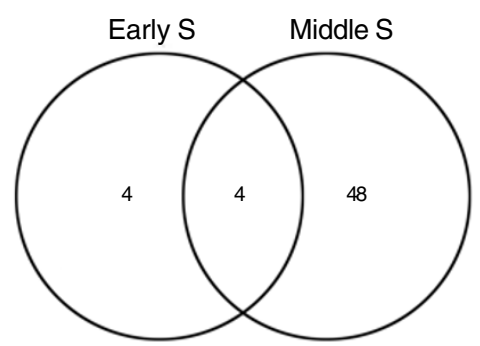

The number of up-regulated genes

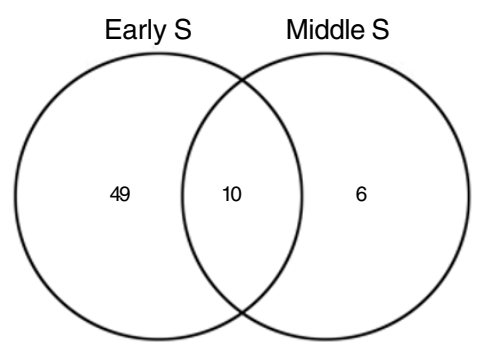

The number of down-regulated genes

Fig. 4 Different responses between TC-treated early-S cells and TC-treated middle-S cells. (A) TC induced different cell-cycle arrests at different stages of $\mathrm{S}$ phase. The early S-phase HeLa cells (released from $\mathrm{G}_{1} / \mathrm{S}$ border for $5 \mathrm{~min}$ ) and middle S-phase (released for 3 h) HeLa cells were treated with $15 \mathrm{ng} / \mathrm{ml} \mathrm{TC}$ respectively. The released cells with no TC treatment were used as controls. Cells were harvested at the indicated times and analyzed with flow cytometry. (B) profiling of genes differentially expressed between TC-treated early-S cells and TC-treated middle-S cells. The early S-phase and middle S-phase HeLa cells were prepared and treated with $15 \mathrm{ng} / \mathrm{ml}$ TC for $13 \mathrm{~h}$, respectively. The untreated early S-phase and middle S-phase cells were used as controls. The microarray assays were performed as described in Materials and Methods. The up-regulated genes (the ratio of TC-treated cells/control is over 1.5) and downregulated genes (the ratio of TC-treated cells/control is below 0.5 ) from the averages of two duplicate experiments were accounted.

respectively. The results showed that the mRNA level of survivin was down-regulated in the TC-treated early-S cells but up-regulated in the TC-treated middle-S cells (Fig. 5B). This change was further confirmed at protein level by Western-blotting analysis (Fig. 5C). In contrast, Westernblotting analysis showed the level of the p53 proteins in- duced after TC treatment was increased to the same extent in both the early-S and middle-S cells (Fig. 5C). The uncovered result of differential expression of survivin suggests that survivin plays an important role in the regulation of the cell-cycle dependent apoptosis. 
A

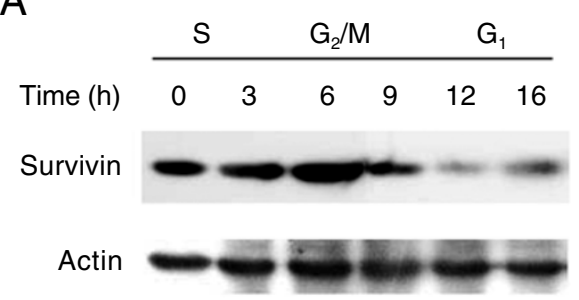

B

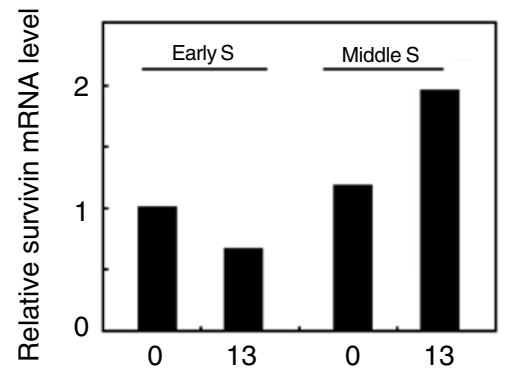

C

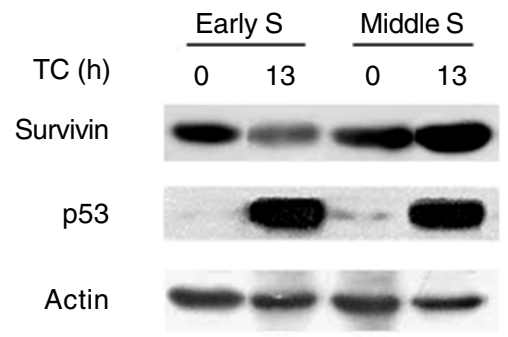

Fig. 5 Survivin differentially expressed between TC-treated early-S cells and TC-treated middle-S cells. (A) expression of survivin in synchronized cells. The cells synchronized at $\mathrm{G}_{1} / \mathrm{S}$ border were released and maintained in fresh medium. The expression of survivin was detected by western blot at the indicated times. (B) relative survivin mRNA level of early-S and middle-S cells in the presence of TC. The early S-phase and middle S-phase HeLa cells were prepared and treated with $15 \mathrm{ng} / \mathrm{ml}$ TC for $13 \mathrm{~h}$, respectively. The relative expression fold of survivin mRNA was got from array data. Result was confirmed with RT-PCR. (C) protein level of survivin and p53 in TC-treated early-S cells and the TC-treated middle-S cells. The early S-phase and middle S-phase HeLa cells were prepared and treated with $15 \mathrm{ng} / \mathrm{ml} \mathrm{TC}$ for $13 \mathrm{~h}$, respectively. Actin was used as sample-loading control.

\section{Differential regulation of survivin by $\mathrm{p53}$ in different stages of the cell cycle in the presence of TC}

It has been well documented that the expression of survivin is down-regulated by $\mathrm{p} 53$, and the repression of survivin is tightly related to p53-dependent apoptosis [29, 41]. Since our results showed that p53 level of the TCtreated early-S cells was activated to the same extent as the TC-treated middle-S cells (Fig. 5C), it is possible that p53 can differentially regulate the survivin expression un-
A

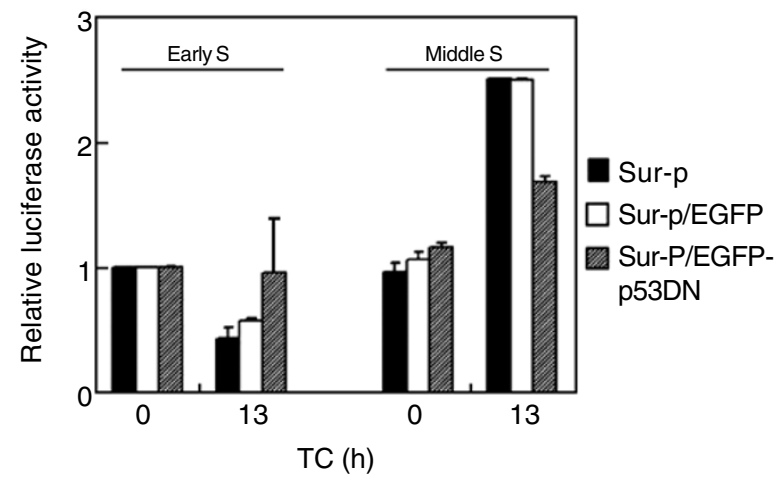

B

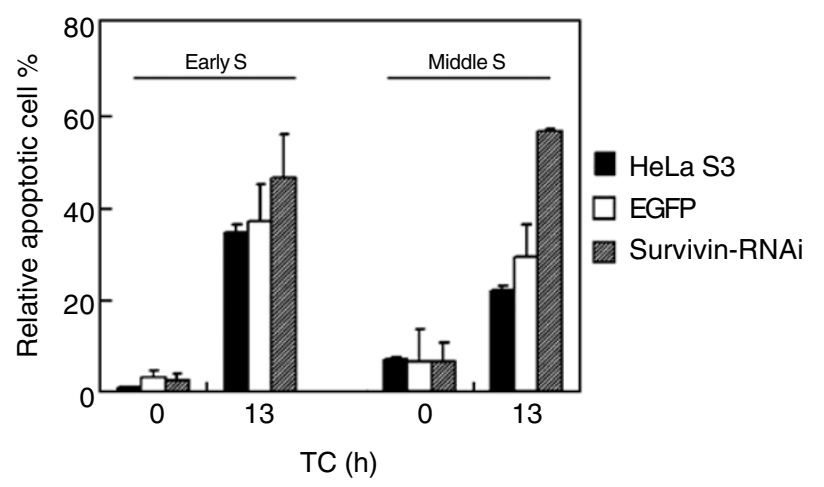

Fig. 6 The expression of survivin differentially regulated by $\mathrm{p} 53$ involves in the cell-cycle dependent apoptosis. (A) p53 differentially regulates the survivin expression in the TC-treated S-phase cells. HeLa S3 cells were transfected with indicated plasmids, respectively, and then synchronized with HU. The cells were treated with $15 \mathrm{ng} / \mathrm{ml}$ TC for $13 \mathrm{~h}$ and subjected to luciferase assay. (B) RNAi of survivin elevates the apoptosis of the TC-treated middle-S cells. HeLa S3 cells were transfected with indicated plasmids, respectively, and then synchronized with HU. The cells were treated with $15 \mathrm{ng} / \mathrm{ml} \mathrm{TC}$ for $13 \mathrm{~h}$, and the apoptotic ratio was counted as described in Fig. 3. Data shown are representative of three separate experiments (mean $\pm \mathrm{SD})$.

der the different cellular context. To address this possibility, a plasmid containing luciferase driven by the promoter of survivin was transfected into HeLa cells and its expression activity was analyzed by luciferase assay. The results showed that the survivin-promoter related expression was down-regulated in the TC-treated early-S cells $(P<0.01)$, and this suppression was abolished by co-transfection of the dominant negative p53 (Fig. 6A). On the other hand, the survivin-promoter related expression was increased in the TC-treated middle-S cells, while the co-transfection of dominant negative p53 inhibited this up-regulated expression (Fig. 6A). These results suggest that the effect 
of p53 on the transcription of survivin in the TC-treated early-S cells is opposite to that in the TC-treated middle-S cells (see Discussion).

The further experiments indicated that the lower percentage of apoptosis in the TC-treated middle-S cells, at least partially, resulted from the up-regulation of survivin expression. HeLa cells transfected with a plasmid containing survivin-RNAi were synchronized to the early and middle $\mathrm{S}$ phase, respectively, and then treated with TC for indicated times. The silencing of survivin enhanced significantly the apoptotic response to TC treatment in the middle-S cells, whereas the apoptotic cells were only slightly increased in the TC-treated early-S population (Fig. 6B). The results support the argument that the up-regulation of survivin contributes to the survival of the middle-S cell in the presence of $\mathrm{TC}$.

\section{DISCUSSION}

The regulation of cell cycle is tightly correlated with apoptotic control when the cells are under external or internal stresses. Our studies indicated that TC-treated HeLa cells in the $\mathrm{S}$ phase, especially in the early $\mathrm{S}$ phase, are highly susceptible to initiation of apoptosis (Fig. 3). This observation was very similar to the results revealed by Schlegel lab [42]. They found that apoptosis was induced in S-phase-arrested HeLa cells by staurosporine, caffeine, 6-dimethylaminopurine or okadaic acid, whereas little amount of apoptosis took place in asynchronously growing cells or in the cells arrested in $G_{1}$ phase under the same treatment [42].

Since the CDK2 activation is a key factor for the transition from $\mathrm{G}_{1}$ to $\mathrm{S}$ phase, it is possible that activated CDK2 links the $\mathrm{S}$ phase and apoptosis. A previous report showed that CDK2 activation during thymocyte apoptosis was regulated by $\mathrm{p} 53$, Bax and Bcl-2 [9]. In addition, the inactivation of CDKs by its dominant negative mutants suppressed the drug-induced apoptosis of HeLa cells [43]. Our microarray analyses here suggest another possibility that the extensive down-regulation of most genes in TCtreated early-S cells results in their susceptibility to apoptosis (Fig. 4B). It will be worth knowing that which factor(s) is responsible for this extensive down-regulation pattern of the early-S cells in the presence of TC.

Survivin, a member of the inhibitor of apoptosis protein (IAP) family, has been revealed to participate the control of apoptosis and $\mathrm{G}_{2} / \mathrm{M}$ checkpoint $[3,44,45]$. It was reported that the expression of survivin was at low level in $G_{1}$ and $S$ phase but was elevated in $G_{2} / M$ phase, and this $G_{2} / M$ specific expression has been related to mitotic spindle checkpoint function [3]. The present studies indicate that survivin also plays an important role in the regulation of apoptosis in S-phase HeLa cell treated with TC.
The results showed that the survivin was up-regulated in the TC-treated middle-S cells (Fig. 5B, 5C), and the suppression of the survivin up-regulation by the RNA interference caused the increase of apoptotic cells (Fig. 6B).

Survivin has been reported as a p53-regulated gene. A number of data show that the transcription of survivin is repressed by $\mathrm{p} 53[29,41]$. In the present studies, the suppression of survivin-promoter by $\mathrm{p} 53$ was identified in the TC-treated early-S cells (Fig. 6A). To our surprise, it was showed that the expression of survivin-promoter was upregulated in the TC-treated middle-S cells, and the up-regulation was diminished by introduction of the p53 dominant negative construct. This result implies that the p53-regulating survivin is much more complicated than the simple repression-diagram. In fact, a previous observation already showed that a correlation between accumulated p53 and survivin expression existed in gastric carcinomas [46].

Since TC treatment caused the same extent of p53 activation in both early-S cells and middle-S cells (Fig. 5C), this result provides a new argument that the particular p53mediated networks rather than p53 molecule alone in the different stages of the cell cycle determine the functional performance of p53 responded to genotoxic stresses. Recently, Dobbelstein's lab argued that the p53-mediated repression of survivin expression depended mainly on the induction of $\mathrm{p} 21^{\mathrm{WAF} 1 / \mathrm{CIP} 1}$ gene [47]. Moreover, another experiment suggested that the modification of chromatin within the survivin promoter rather than p53-binding sites in the survivin promoter could be for the p53-regulated suppression of survivin transcription [41].

Bernard et al. showed that the p53 activity might involve in the apoptotic susceptibility of HPV infected cells when they compared the HPV-positive cells containing wild type p53 with the HPV-negative cells containing mutated p53 [15]. Our results here demonstrated that the cell-cycle dependent apoptosis was related with the differential transregulation of p53 on the basis of the silencing of E6 and restoration of functional p53. It is well documented the oncoprotein E6 expressed by human papillomavirus (HPV) neutralizes the functions of tumor suppressor p53 by promoting p53 degradation, which represents a key step in cervical carcinogenesis [32, 48, 49]. Therefore, one of therapeutic strategies for cervical tumors is to repress the expression of HPV oncogenes and then re-activate the tumor-suppress genes. Recently, Lane's lab reported that the anti-tumor compounds, leptomycin B and actinomycin D, reduced the expression of HPV E6/E7 mRNA in HeLa cells, which is a cervical cancer-derived cell line, and resulted in the activation of p53 [30]. The experiments presented here demonstrated that TC also significantly decreased the expression of E6/E7 mRNA and increased the p53 expression (Fig. 3). Our results suggest that TC 
can be used as a potential anti-tumor reagent in the treatment of cervical cancer.

\section{ACKNOWLEDGEMENTS}

This work was supported by a grant of National Natural Science Foundation of China (No. 30230110), a grant of Science and Technology Committee of Shanghai Municipality (No. 04DZ14901), and a grant of Chinese Academy of Sciences \#KSCX2-SW-203 to Jia Rui WU. We thank Dr. Yuan Chao LI of Institute of Materia Medica, SIBS, CAS who kindly provided TC compound.

Received, Mar 1, 2005

Revised, Apr 12, 2005

Accepted, Apr 15, 2005

\section{REFERENCES}

1 Strasser A, Harris AW, Bath ML, Cory S. Novel primitive lymphoid tumours induced in transgenic mice by cooperation between myc and bcl-2. Nature 1990; 348:331-3.

2 Hanahan D, Weinberg RA. The hallmarks of cancer. Cell 2000; 100:57-70.

3 Li F, Ambrosini G, Chu EY, et al. Control of apoptosis and mitotic spindle checkpoint by survivin. Nature 1998; 396:580-4.

4 Dobles M, Liberal V, Scott ML, Benezra R, Sorger PK. Chromosome missegregation and apoptosis in mice lacking the mitotic checkpoint protein Mad2. Cell 2000; 101:635-45.

5 O'Connor DS, Grossman D, Plescia J, et al. Regulation of apoptosis at cell division by $\mathrm{p} 34 \mathrm{cdc} 2$ phosphorylation of survivin. Proc Natl Acad Sci U S A 2000; 97:13103-7.

6 Vermeulen K, Berneman ZN, Van Bockstaele DR. Cell cycle and apoptosis. Cell Prolif 2003; 36:165-75.

7 Adachi S, Obaya AJ, Han Z, et al. c-Myc is necessary for DNA damage-induced apoptosis in the $\mathrm{G}(2)$ phase of the cell cycle. Mol Cell Biol 2001; 21:4929-37.

8 Yonish-Rouach E, Grunwald D, Wilder S, et al. p53-mediated cell death: relationship to cell cycle control. Mol Cell Biol 1993; 13:1415-23.

9 Gil-Gomez G, Berns A, Brady HJ. A link between cell cycle and cell death: Bax and Bcl-2 modulate Cdk2 activation during thymocyte apoptosis. EMBO J 1998; 17:7209-18.

10 Vogelstein B, Lane D, Levine AJ. Surfing the p53 network. Nature 2000; 408:307-10.

11 Agarwal ML, Taylor WR, Chernov MV, Chernova OB, Stark GR. The p53 network. J Biol Chem 1998; 273:1-4.

$12 \mathrm{Xu} \mathrm{H}$, el-Gewely MR. P53-responsive genes and the potential for cancer diagnostics and therapeutics development. Biotechnol Annu Rev 2001; 7:131-64.

13 Szak ST, Mays D, Pietenpol JA. Kinetics of p53 binding to promoter sites in vivo. Mol Cell Biol 2001; 21:3375-86.

14 Gorczyca W, Gong J, Ardelt B, Traganos F, Darzynkiewicz Z. The cell cycle related differences in susceptibility of HL-60 cells to apoptosis induced by various antitumor agents. Cancer Res 1993; 53:3186-92.

15 Bernard B, Fest T, Pretet JL, Mougin C. Staurosporine-induced apoptosis of HPV positive and negative human cervical cancer cells from different points in the cell cycle. Cell Death Differ 2001; 8:234-44.

16 McCabe MJ Jr, Singh KP, Reddy SA, et al. Sensitivity of myelomonocytic leukemia cells to arsenite-induced cell cycle disruption, apoptosis, and enhanced differentiation is dependent on the inter-relationship between arsenic concentration, duration of treatment, and cell cycle phase. J Pharmacol Exp Ther 2000; 295:724-33.

17 Offer H, Zurer I, Banfalvi G, et al. p53 modulates base excision repair activity in a cell cycle-specific manner after genotoxic stress. Cancer Res 2001; 61:88-96.

18 Wei YS, Adachi I. Inhibitory effect of triptolide on colony formation of breast and stomach cancer cell lines. Zhongguo Yao Li Xue Bao 1991; 12:406-10.

19 Shamon LA, Pezzuto JM, Graves JM, et al. Evaluation of the mutagenic, cytotoxic, and antitumor potential of triptolide, a highly oxygenated diterpene isolated from Tripterygium Wilfordii. Cancer Lett 1997; 112:113-7.

20 Kiviharju TM, Lecane PS, Sellers RG, Peehl DM. Antiproliferative and proapoptotic activities of triptolide (PG490), a natural product entering clinical trials, on primary cultures of human prostatic epithelial cells. Clin. Cancer Res 2002; 8:2666-74.

21 Lee KY, Chang W, Qiu D, Kao PN, Rosen GD. PG490 (triptolide) cooperates with tumor necrosis factor-alpha to induce apoptosis in tumor cells. J Biol Chem 1999; 274:13451-5.

22 Qiu D, Zhao G, Aoki Y, et al. Immunosuppressant PG490 (triptolide) inhibits T-cell interleukin-2 expression at the level of purine-box/nuclear factor of activated T-cells and NF-kappaB transcriptional activation. J Biol Chem 1999; 274:13443-50.

23 Zhao G, Vaszar LT, Qiu D, Shi L, Kao PN. Anti-inflammatory effects of triptolide in human bronchial epithelial cells. Am J Physiol Lung Cell Mol Physiol 2000; 279:L958-66.

24 Jiang XH, Wong BC, Lin MC, et al. Functional p53 is required for triptolide-induced apoptosis and AP-1 and nuclear factorkappaB activation in gastric cancer cells. Oncogene 2001; 20: 8009-18.

25 Yu DQ, Zhang DM, Wang HB, Liang XT. Structure modification of triptolide, a diterpenoid from Tripterygium Wilfordii. Yao Xue Xue Bao 1992; 27:830-6.

26 Ren Y, Xiong L, Wu JR. Induction of mitochondrion-mediated apoptosis of CHO cells by tripchlorolide. Cell Res 2003; 13:95300.

27 Jiang MR, Li YC, Yang Y, Wu JR. c-Myc degradation induced by DNA damage results in apoptosis of CHO cells. Oncogene 2003; 22:3252-9.

28 Lee H, Larner JM, Hamlin JL. Cloning and characterization of Chinese hamster p53 cDNA. Gene 1997; 184:177-83.

29 Hoffman WH, Biade S, Zilfou JT, Chen J, Murphy M. Transcriptional repression of the anti-apoptotic survivin gene by wild type p53. J Biol Chem 2002; 277:3247-57.

30 Hietanen S, Lain S, Krausz E, Blattner C, Lane DP. Activation of p53 in cervical carcinoma cells by small molecules. Proc Natl Acad Sci U S A 2000; 97:8501-6.

31 Goodwin EC, DiMaio D. Repression of human papillomavirus oncogenes in HeLa cervical carcinoma cells causes the orderly reactivation of dormant tumor suppressor pathways. Proc Natl Acad Sci U S A 2000; 97:12513-8.

32 Scheffner M, Huibregtse JM, Vierstra RD, Howley PM. The HPV-16 E6 and E6-AP complex functions as a ubiquitin-protein 
ligase in the ubiquitination of $\mathrm{p} 53$. Cell 1993; 75:495-505.

33 Siliciano JD, Canman CE, Taya Y,et al. DNA damage induces phosphorylation of the amino terminus of p53. Genes Dev 1997; 11:3471-81.

34 Tibbetts RS, Brumbaugh KM, Williams JM, et al. A role for ATR in the DNA damage-induced phosphorylation of p53. Genes Dev 1999; 13:152-7.

35 Sgonc R, Gruber J. Apoptosis detection: an overview. Exp Gerontol 1998; 33:525-33.

36 Vermes I, Haanen C, Steffens-Nakken H, Reutelingsperger C. A novel assay for apoptosis. Flow cytometric detection of phosphatidylserine expression on early apoptotic cells using fluorescein labelled Annexin V. J Immunol Methods 1995; 184:39-51.

37 Leers MP, Kolgen W, Bjorklund V, et al. Immunocytochemical detection and mapping of a cytokeratin 18 neo-epitope exposed during early apoptosis. J Pathol 1999; 187:567-72.

38 Biven K, Erdal H, Hagg M, et al. A novel assay for discovery and characterization of pro-apoptotic drugs and for monitoring apoptosis in patient sera Apoptosis 2003; 8:263-8.

39 Altieri DC. Survivin, versatile modulation of cell division and apoptosis in cancer. Oncogene 2003; 22:8581-9.

40 Lens SM, Wolthuis RM, Klompmaker R, et al. Survivin is required for a sustained spindle checkpoint arrest in response to lack of tension. EMBO J 2003; 22:2934-47.

41 Mirza A, McGuirk M, Hockenberry TN, et al. Human survivin is negatively regulated by wild-type p53 and participates in p53-dependent apoptotic pathway. Oncogene 2002; 21:2613-
22.

42 Meikrantz W, Gisselbrecht S, Tam SW, Schlegel R. Activation of cyclin A-dependent protein kinases during apoptosis. Proc Natl Acad Sci U S A 1994; 91:3754-8.

43 Meikrantz W, Schlegel R. Suppression of apoptosis by dominant negative mutants of cyclin-dependent protein kinases. J Biol Chem 1996; 271:10205-9.

44 LaCasse EC, Baird S, Korneluk RG, MacKenzie AE. The inhibitors of apoptosis (IAPs) and their emerging role in cancer. Oncogene 1998; 17:3247-59.

45 Beltrami E, Plescia J, Wilkinson JC, Duckett CS, Altieri DC. Acute ablation of survivin uncovers p53-dependent mitotic checkpoint functions and control of mitochondrial apoptosis. J Biol Chem 2004; 279:2077-84.

$46 \mathrm{Lu}$ CD, Altieri DC, Tanigawa N. Expression of a novel antiapoptosis gene, survivin, correlated with tumor cell apoptosis and p53 accumulation in gastric carcinomas. Cancer Res 1998; 58:1808-12.

47 Lohr K, Moritz C, Contente A, Dobbelstein M. p21/CDKN1A mediates negative regulation of transcription by $\mathrm{p} 53$. J Biol Chem 2003; 278:32507-16.

48 Slebos RJ, Lee MH, Plunkett BS, et al. p53-dependent G1 arrest involves pRB-related proteins and is disrupted by the human papillomavirus 16 E7 oncoprotein. Proc Natl Acad Sci U S A 1994; 91:5320-4.

49 Tommasino M, Accardi R, Caldeira S, et al. The role of TP53 in Cervical carcinogenesis. Hum Mutat 2003; 21:307-12. 